\title{
Revised Mimivirus major capsid protein sequence reveals intron-containing gene structure and extra domain Saïd Azza ${ }^{1}$, Christian Cambillau ${ }^{2}$, Didier Raoult ${ }^{1}$ and Marie Suzan-Monti*1
}

Address: ${ }^{1}$ Unité de Recherche sur les Maladies Infectieuses et Tropicales Emergentes (URMITE), CNRS-IRD UMR 6236, IFR 48, Faculté de Médecine, 27 Boulevard Jean Moulin, 13385 Marseille cedex 05, France and ²Architecture et Fonction des Macromolécules Biologiques, UMR 6098, CNRS-Universités Aix-Marseille I et II, Campus de Luminy, Case 932, 163 Avenue de Luminy, 13288 Marseille cedex 09, France

Email: Saïd Azza - said.azza@univmed.fr; Christian Cambillau - cambillau@afmb.univ-mrs.fr; Didier Raoult - didier.raoult@univmed.fr; Marie Suzan-Monti* - marie.suzan@univmed.fr

* Corresponding author

Published: II May 2009

BMC Molecular Biology 2009, 10:39 doi:10.1 186/1471-2199-10-39

This article is available from: http://www.biomedcentral.com//47/-2/99//0/39

(C) 2009 Azza et al; licensee BioMed Central Ltd.

This is an Open Access article distributed under the terms of the Creative Commons Attribution License (http://creativecommons.org/licenses/by/2.0), which permits unrestricted use, distribution, and reproduction in any medium, provided the original work is properly cited.
Received: 9 July 2008

Accepted: II May 2009

\begin{abstract}
Background: Acanthamoebae polyphaga Mimivirus (APM) is the largest known dsDNA virus. The viral particle has a nearly icosahedral structure with an internal capsid shell surrounded with a dense layer of fibrils. A Capsid protein sequence, DI3L, was deduced from the APM L425 coding gene and was shown to be the most abundant protein found within the viral particle. However this protein remained poorly characterised until now. A revised protein sequence deposited in a database suggested an additional $\mathrm{N}$-terminal stretch of 142 amino acids missing from the original deduced sequence. This result led us to investigate the $L 425$ gene structure and the biochemical properties of the complete APM major Capsid protein.
\end{abstract}

Results: This study describes the full length 3430 bp Capsid coding gene and characterises the 593 amino acids long corresponding Capsid protein I. The recombinant full length protein allowed the production of a specific monoclonal antibody able to detect the Capsid protein I within the viral particle. This protein appeared to be post-translationnally modified by glycosylation and phosphorylation. We proposed a secondary structure prediction of APM Capsid protein I compared to the Capsid protein structure of Paramecium Bursaria Chlorella Virus I, another member of the Nucleo-Cytoplasmic Large DNA virus family.

Conclusion: The characterisation of the full length L425 Capsid coding gene of Acanthamoebae polyphaga Mimivirus provides new insights into the structure of the main Capsid protein. The production of a full length recombinant protein will be useful for further structural studies.

\section{Background}

Acanthamoebae polyphaga Mimivirus was described for the first time in 2003 [1]. It was isolated from amoebae growing in water sample from a cooling tower during an outbreak of pneumonia in an English hospital. Compared to other members of the Nucleo-Cytoplasmic Large DNA Viruses (NCLDV) family [2], APM has very particular char- acteristics due to its size, structure, genome sequence [3], and replication cycle through a specific virus factory [4]. The virus particle was shown to be icosahedral, with a capsid shell diameter of $5000 \AA$ covered by long fibers and appears to have at least two lipid membranes beneath its Capsid protein [5]. The APM 1.2-Mb genome encodes at least 911 proteins [Genbank: NC 006450] [6]. Proteomic 
analysis of proteins extracted from purified viral particles allowed the identification of 114 proteins including the Capsid protein D13L, coded by the $\mathrm{L} 425$ gene. The D13L Capsid protein was shown to be the most abundant and major glycoprotein of APM [7] and is thought to be the main component of the outermost protein shell layer. The protein sequence was deduced from the first available Methionine codon in the L425 open reading frame. Recently, based on mass spectrometry analysis of the Capsid protein $\mathrm{D} 13 \mathrm{~L}$ peptides, the original protein sequence was revised and completed with 142 supplementary $\mathrm{N}$ terminal amino-acids (AA) [UniProtKB: Q5UQL7] [8] and thereafter named here Capsid protein 1 . The aim of this study was to characterize the full length APM Capsid protein 1 coding gene and to provide new insights into the structure of the protein. Blast of the Capsid protein 1 coding sequence on the APM genome sequence revealed that the start codon might be located 2042 bp upstream from the start codon of the previously annotated L425 coding gene. We produced a recombinant full length Capsid protein 1 and specific monoclonal antibodies (mAb) that might be useful to develop further structural analysis or detection assays.

\section{Methods \\ cDNA cloning and sequencing}

Total RNA from uninfected or APM infected A. polyphaga was extracted using RNeasy extraction kit (Qiagen) as previously described [3]. The Capsid protein 1 cDNA was synthsesized from APM infected A. polyphaga RNA by using the Superscript One-Step RT-PCR with Platinum Taq kit (Invitrogen) with the following primers:

Q5UQL7NCoIF: 5'-GAAGGAGATATACCATGGCAGGTGGTTTACTCCAATTA-3' and Q5UQL7SmaIR: 5'GATGAGAACCCCCCCCGGGATTACTG-

TACGCTAATCCG-3'. Underlined are the APM L425 gene specific sequences: nt 560926 - 560449 for the forward primer; nt 557533 - 557515 for the reverse primer. The resulting $1782 \mathrm{bp}$ cDNA fragment was then cloned into the pIVEX 2.3 expression vector (Roche) at the NcoI and SmaI sites. Recombinant plasmids were selected, purified and then incorporated into the d-Rhodamine Terminator Cycle Sequencing Ready Reaction buffer kit with Amplitaq Polymerase FS (Applied Biosystems). Reaction products were resolved by using an ABI 3100 automated sequencer and sequence analysis was performed using the software package ABI Prism DNA Sequencing Analysis Software version 3.0 (Applied Biosystems). T7 promoter and T7 terminator primers were used as well as two primer pairs targeting internal regions of the cDNA: QUQL7-SF1: 5'-GCTGGCAGTAGTAATTCTGC-3'; QUQL7-SR1: 5'GCAGAATTACTACTGCCAGC-3'; and QU5QL7-SF2: 5'GAAGGTAATGATGGTAGAAG-3'; QU5QL7-SR2: 5'CTTCTACCATCATTACCTTC-3'.

\section{RT-PCR analysis}

RNA was extracted from uninfected or APM-infected amoebae at $0,2,4,8$ and 16 hours post infection. $100 \mathrm{ng}$ of each RNA was submitted to RT-PCR amplification using the SuperScript One-Step RT-PCR kit (Invitrogen) with the Q5UQL7NcoIF/Q5UQL7SmaIR primer pair. cDNA synthesis was performed in one cycle of 30 minutes at $50^{\circ} \mathrm{C}, 3$ minutes at $94^{\circ} \mathrm{C}$ and subsequent PCR reaction with 35 cycles of 30 seconds at $94^{\circ} \mathrm{C}, 30$ seconds at $60^{\circ} \mathrm{C}$, 30 seconds at $72^{\circ} \mathrm{C}$, and one cycle of 10 minutes at $72^{\circ} \mathrm{C}$. Amplified products were analysed by electrophoresis on $1 \%$ agarose gel. GeneRuler $1 \mathrm{~kb}$ DNA ladder (MBI-Fermentas) was used as a DNA size marker.

\section{Expression of the recombinant Capsid protein I}

Expression of the Capsid protein 1 was performed using a cell-free translation system [9], the High Yield RTS 500 Escherichia coli Circular Template kit (Rapid Translation System, Roche). Reactions were performed at $30^{\circ} \mathrm{C}$ for 24 $\mathrm{h}$, with a stirrer speed of $120 \mathrm{rpm}$, with $15 \mu \mathrm{g}$ of recombinant plasmid used as DNA template. The RTS sample was then centrifuged for $10 \mathrm{~min}$ at $10000 \mathrm{rpm}$ and the pellet was resuspended in Laemmli buffer, heated for 5 min at $95^{\circ} \mathrm{C}$, resolved by $7.5 \%$ SDS-PAGE, followed by Coomassie blue staining or transfer onto nitrocellulose membrane for immunoblot analysis using a anti-Histidine monoclonal antibody. The recombinant Capsid protein 1 was extracted from polyacrylamide gels by the electroelution method using the ElutaTube ${ }^{\mathrm{TM}}$ Protein Extraction Kit (Fermentas Life Sciences) according to the manufacturer's protocol and used to immunise mice for the production of monoclonal antibodies.

\section{Monoclonal antibodies production}

Three six week-old female BALB/c mice were inoculated three times intraperitoneally at 14-days interval with $2 \mu \mathrm{g}$ electroeluted protein mixed with $400 \mu \mathrm{g}$ aluminium hydroxide and $10 \mu \mathrm{g}$ CpG as previously described [10]. Four days after the last immunisation, spleen cells fusion was performed with X63.Ag 8.653 myeloma cells (2:1) using 50\% 1500 polyethylene glycol (Roche). Cells were grown in RPMI medium (Invitrogen) with $15 \%$ heat inactivated fetal calf serum (Invitrogen) and hypoxanthineaminopterin-thymidine selective medium (Invitrogen) at $37^{\circ} \mathrm{C}$ with $5 \% \mathrm{CO} 2$. Hybridoma supernatants were screened 10 days after by ELISA using plates coated overnight with $10 \mu \mathrm{g} / \mathrm{ml}$ of APM extract in sodium carbonate buffer $100 \mathrm{mM}, \mathrm{pH}$ 9.6. Positive hybridomas were subcloned by limiting dilution and submitted to isotyping using a mouse monoclonal isotyping kit (Sigma-Aldrich). Hybridomas producing the highest mAb titers were then subcloned, expanded, and tested by Western blot analysis using APM extract subjected to 2D gel electrophoresis and transferred onto nitrocellulose. 


\section{D-gel electrophoresis}

APM particles were purified through a $25 \%$ sucrose gradient and APM extract was prepared for 2-D gel electrophoresis as previously reported [7]. Immobiline ${ }^{\mathrm{TM}}$ DryStrips (7 cm, pH 3-10 GE Healthcare) were rehydrated overnight using $125 \mu$ l rehydration buffer [8 M urea, 2\% (w/v) CHAPS, $60 \mathrm{mM}$ DTT, 0,5\% (v/v) IPG buffer (GE Healthcare)] containing $20 \mu \mathrm{g}$ of solubilized APM proteins and IEF was carried out according to the manufacturer's protocol (IPGphor II, GE Healthcare). Before the second dimension electrophoresis was performed, strips were equilibrated twice in $5 \mathrm{ml}$ equilibration buffer [30\% (v/v) glycerol, 3\% (w/v) SDS, $6 \mathrm{M}$ urea, $50 \mathrm{mM}$ Tris-HCl, bromophenol blue, $\mathrm{pH} 8.8$ ] for $15 \mathrm{~min}$. This buffer was supplemented with $65 \mathrm{mM}$ DTT for the first equilibration and with $100 \mathrm{mM}$ iodoacetamide for the second one. The strips were then embedded in $0.5 \%$ agarose and the proteins resolved by $10 \%$ SDS-PAGE (Mini-Protean III, Bio-Rad). Gels were stained either with silver or transferred onto nitrocellulose for Western blot analysis using Capsid protein 1 specific $\mathrm{mAb}$; anti-Phosphothreonine, anti-Phosphotyrosine or anti-Phosphoserine $\left(10^{-4}\right.$ dilution, Sigma) mAbs; or rabbit polyclonal antiserum anti-methylated Lysine (dilution $4.10^{-2}$, Bio$\mathrm{mol} \mathrm{GmbH)}$. The detection of glycosylated proteins in 2D gels was performed according to the Pro-Q Emeral 300 glycoprotein stain kit's procedure (Invitrogen) and visualized using a $300 \mathrm{~nm}$ UV illuminator.

\section{Results and discussion}

The L425 gene (nt 557530 - 558 885) was originally annotated as being the APM D13L Capsid protein coding sequence. Further mass spectrometry identification of D13L Capsid peptides allowed Suhre et al. to submit a protein sequence completed with $142 \mathrm{~N}$-terminal AA [8]. Using TBLASTN [11] the coordinates of the corresponding nucleotide sequence on the APM genome appeared to be: nt 560926 - 560867 (coding AA 1-18); nt 559681 - 559 658 (coding AA 19-27) and nt 559233 - 557533 (coding AA 27-593). This result suggested the existence of two untranslated regions: intron 1, 1188 bp long, (nt 560868 - 559 680) and intron 2, 427 bp long (nt 559659 - 559 232) (Figure 1A).

Based on this sequence, outermost 5'- and 3'-terminal primers, Q5UQL7NcoIF and Q5UQL7SmaIR respectively, were designed to determine the Capsid protein 1 gene structure. RNA was extracted from APM-infected A. polyphaga and used to synthetise full length L425 cDNA. We then cloned the full-length cDNA into an expression vector and sequenced the target gene. Comparison of the cDNA sequence (1782 bp) with the APM genomic DNA sequence confirmed that the Capsid protein 1 gene is $3430 \mathrm{bp}$ long and consists of three exons interrupted by two introns (Figure 1A). This result supposed that splicing events might occur during gene transcription and/or RNA maturation. To gain insight into this possibility, RT-PCR analyses were performed on RNA extracted at different time from APM-infected A. polyphaga using the Q5UQL7NcoIF/Q5UQL7SmaIR primer pair (Figure 1B). Agarose gel electrophoresis showed a fragment, about $4000 \mathrm{bp}$ long, amplified from APM genomic DNA (lane 1), and a fragment, about $1800 \mathrm{bp}$ long, from infected cell RNA (lanes 3-7), while no fragment was amplified from uninfected cell RNA (lane 2). Only fully spliced mRNA was detected from to to t16 p.i., with an increased signal. No precursor RNA could be identified. Detection of Capsid protein 1 mRNA as soon as t0 was not surprising since this RNA was shown to be packaged within the viral particle [3]. Additional RT-PCR experiments performed using primer pairs able to detect the potential different forms of spliced Capsid protein 1 RNA were unsuccessful to demonstrate alternative forms of spliced RNA whatever the time post-infection (data not shown).

The full length 1782 bp Capsid protein 1 cDNA codes a 593 AA polypeptide with an estimated molecular mass of $67.27 \mathrm{kDa}$ and theoretical isoelectric point of 5.27. The full length cDNA was cloned into the pIVEX 2.3 expression vector, producing a C-terminal His-tagged recombinant protein. Analysis of the purified recombinant protein revealed an apparent molecular weight of 69.61 $\mathrm{kDa}$, in accordance with the calculated one (Figure 2). Expression of Capsid protein 1 was also successful in $E$. coli BL21 (DE3) pLysS. The protein was found in the unsoluble fraction and Western blot analysis using antiHis antibodies revealed the same pattern as with the in vitro translated protein (data not shown).

Analysis of proteins extracted from purified APM particles, resolved by 2D gel electrophoresis, revealed after silver staining the typical electrophoresis pattern of APM proteins with the Capsid protein 1 appearing as four spots under silver staining with an apparent $68.95 \mathrm{kDa}$ molecular weight (Figure 3A and [7]). Monoclonal antibodies $(\mathrm{mAb})$ produced against the recombinant full length Capsid protein 1 were used for Western blot analysis of APM extract resolved by 2D gel analysis and transferred onto nitrocellulose membranes. The anti-Capsid protein 1 mAb P9A3 recognized the spots previously identified by mass spectrometry as the Capsid protein D13L (Figure $3 \mathrm{~B})$. It was previously shown that rabbit or mouse polyclonal antisera prepared against purified viral particles were unable to recognize any of these spots and that the D13L capsid protein was shown to be glycosylated [7]. APM Capsid protein 1 contains several Ser, Thr or Asn residues predicted to be $\mathrm{N}$ - or O-glycosylated, according to sequence analysis using the ExPASy proteomics server (data not shown) [12], but has no signal peptide. The absence of signal peptide suggests that APM Capsid pro- 
A

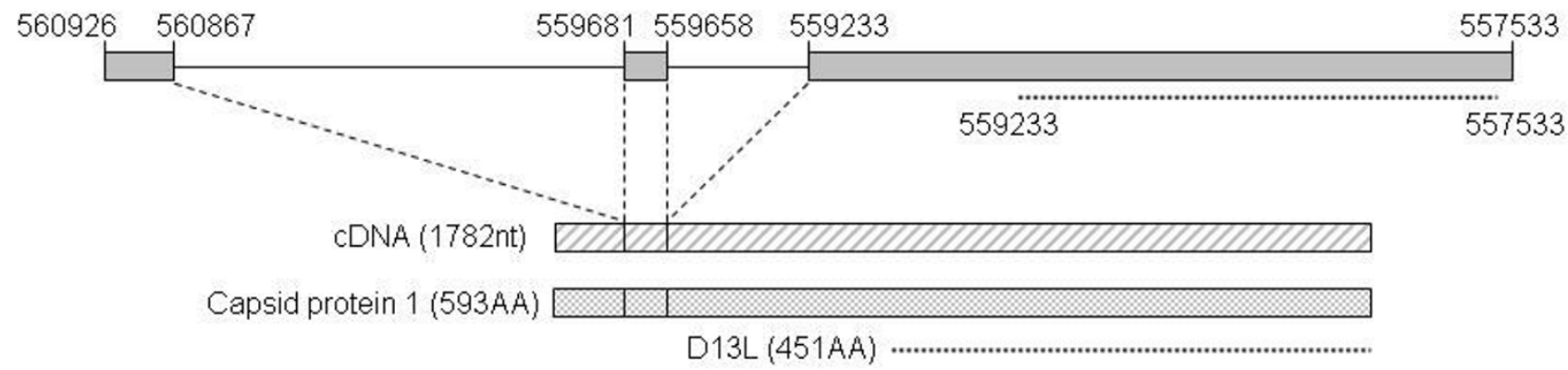

B

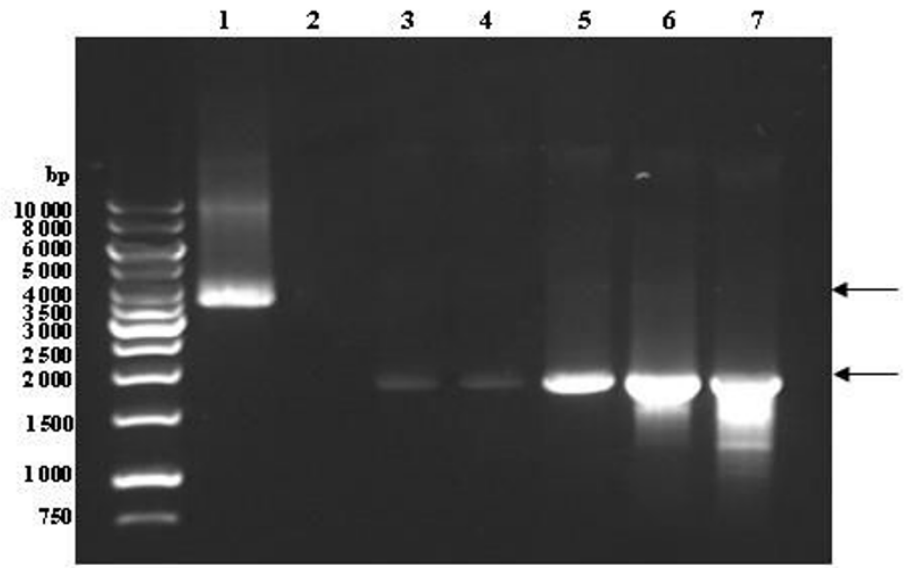

Figure I

Schematic organisation and expression of the full length L425 gene. (A) L425 gene (nt 560926 - 557533 position on the APM genomic DNA) showed three coding sequences, boxed in grey, separated by two intron sequences. Organisation of the corresponding CDNA and 593AA full length protein are shown below. Locations of the former DI3L capsid coding sequence and corresponding protein are indicated by dotted lines. (B) PCR on APM genomic DNA (lane I) and RT-PCR analysis on RNA extracted from uninfected (lane 2) or APM-infected amoebae at 0, 2, 4, 8 and 16 h p.i. (lanes 3-7, respectively) using 5' Q5UQL7NcolF and 3' Q5UQL7SmalR primers. Left lane: DNA size marker.

tein 1 potential glycosylation sites are unlikely to be exposed to host cell glycosyltransferases. It has been shown in the PBCV1 Vp54 Capsid protein that N-glycosylation sites around Asn residues do not obey the consensus NX(T/S) motif, meaning that glycosylation may occur via the virus encoded glycosyltransferases rather by the host ones [13]. This may also be the case for APM Capsid protein 1 . Other post-translational modifications were investigated such as AA phosphorylation or methylation. APM Capsid protein 1 appeared to be phosphorylated on Serine (Figure 3C), Threonine or Tyrosine residues but was not methylated (data not shown).

The former coding sequence assignment for the geneL425 was shown to be homologous to Vp54, the major Capsid proteins of Paramecium Bursaria Chlorella Virus 1 (PBCV1) and other large DNA viruses [14]. The full length APM Capsid protein 1 expressed from the L425 gene exhibited even higher sequence identity with Vp54 with 46\% identity in the N-terminal region (positions 1-287) and $40 \%$ in the C-terminal region (positions 483-593). The APM Capsid protein 1 is overall $45 \%$ identical to that of the Chlorella virus PBCV1 [PDB:1J5Q] [15] but 200 aminoacids are inserted at a position of a stretch of 50 residues in the Chlorella virus Capsid protein, between Trp264 and Ser315 (Figure 4A). The insertion has several distinct features: i) it is located at the external face of the APM Capsid protein 1; ii) it does not belong to the two «jelly roll» motifs of the core, as found in PBCV1 Capsid protein; iii) it replaces a group of $4 \mathrm{~N}$-linked sugar, either because Asn residues are in the deletions/insertions sequence areas ( 3 cases) or are absent; and iv) it is pre- 


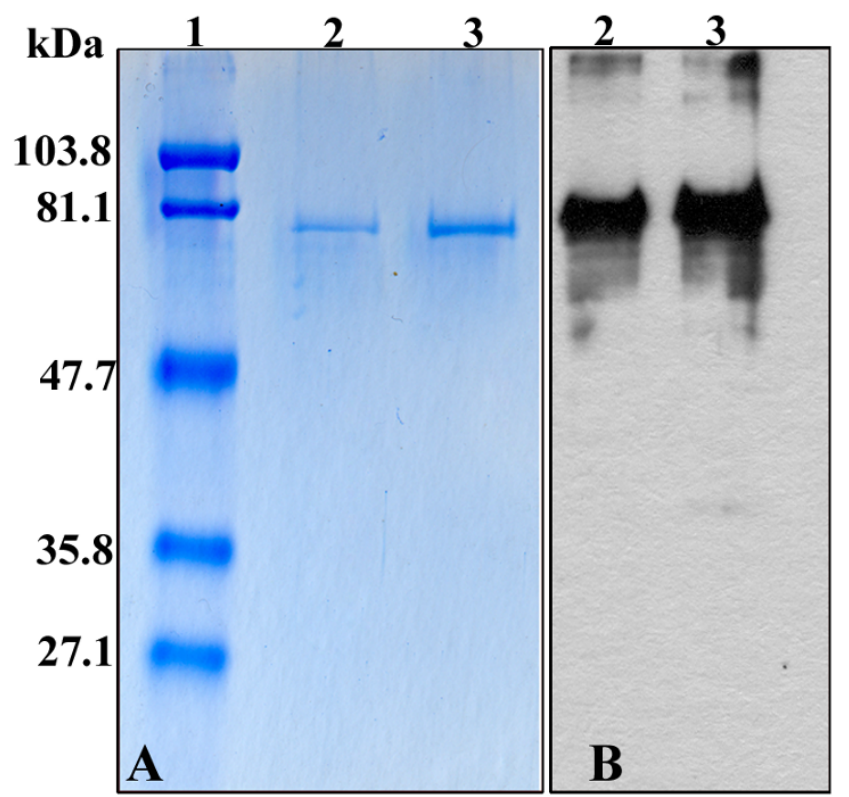

Figure 2

Detection of the purified recombinant Capsid protein I. Either 0.5 or I $\mu \mathrm{g}$ of protein (lanes 2 and 3 respectively) was electrophoresed onto I0\% SDS-PAGE and revealed by Coomassie blue staining $(A)$ or Western-blot analysis using anti-Histidine $\mathrm{mAb}$. Standard molecular weight markers (lane I) are indicated on the left.

dominantly structured as a motif of about $10 \beta$-strands according to the PSIPRED protein structure prediction server [16-18]. Such a high $\beta$-strand contain is reminiscent of $\beta$-sandwich folds. The structure of PBCV1 Capsid is known [16] and is shown in Figure 4B. This structure is formed of two «jelly roll» motifs as found in many other viruses [14]. Compared to the PBCV1 Capsid structure, the APM CApsid protein 1 insertion might be very proeminent. It contains 4 Cysteine residues, on top of the 3 present in the core domain. It should be noticed that PBCV1 contains only 3 Cysteine residues, none of them involved in disulfide bridges. The presence of these conserved domains in the capsid proteins of large dsDNA viruses strengthens the hypothesis that the capsomer structure of APM should be similar to other large dsDNA icosahedral viruses where the capsid proteins assemble into a pseudo-hexameric capsomer organized into tri- and pentasymmetrons [19].

\section{Conclusion}

Due to an erroneous gene model prediction, the coding sequence for L425 was wrongly assigned and was until now only partially described [3]. The full length coding gene appeared to be composed of three exons separated by two untranscribed introns. This leads to the synthesis of a full length 593AA protein translated from a spliced
RNA. This feature seems to be unique to APM since the PBCV1 A383R or the ASFV B646L capsid coding genes do not contain intron sequence $[20,21]$. Tentative bioinformatics analyses of the APM L425 gene introns provided poor informations about their sequences. Intron 1 (nt 560868 - 559680 ) matched with an evalue of 1 e- 4 to group I introns while being not related to a specific subgroup [22,23]. Intron 2 (nt 559659 - 559 232) did not show significant match with either group I or group II introns [22]. Until now, the only other described introns in APM genome are self-splicing introns present in the coding sequences of the two largest RNA polymerase subunits coding genes L244 and R501 [3].

Rabbit or mouse immune sera produced against purified APM particles were unable to recognize the Capsid protein as an antigen in intact viruses, most probably due to the presence of a dense layer of fibrils surrounding the capsid shell. The availability of a monoclonal antibody against Capsid protein 1 might be useful for the development of detection assays in clinical samples since APM might represent a novel human pathogen [24-26].

APM Capsid protein 1 is a glycosylated protein. However its sequence contained no signal peptide, which makes the potential glycosylation sites unlikely to be exposed to the cellular glycosylation machinery. Post-translation modifications might occur in the virus factory since viral proteins appeared to be synthesised herein $[3,4]$. It might be thought that APM possibly use alternative pathways for translation and post-translational modifications. Metabolic studies on APM infected amoebae will contribute to understanding the complex interactions between host and pathogen. The recombinant full length Capsid protein might also represent a helpful tool to determine the structural organisation of APM viral capsid.

Annotation of APM genome revealed 1262 putative ORFs of length $=100$ amino acid residues. 911ORFs were predicted to be protein coding genes and 298 of them had functional attributes [3]. Description of the full length Capsid coding gene and characterisation of the corresponding protein demonstrated that structural and functional studies will contribute to improve our knowledge of gene composition and expression of such a complex genome. 

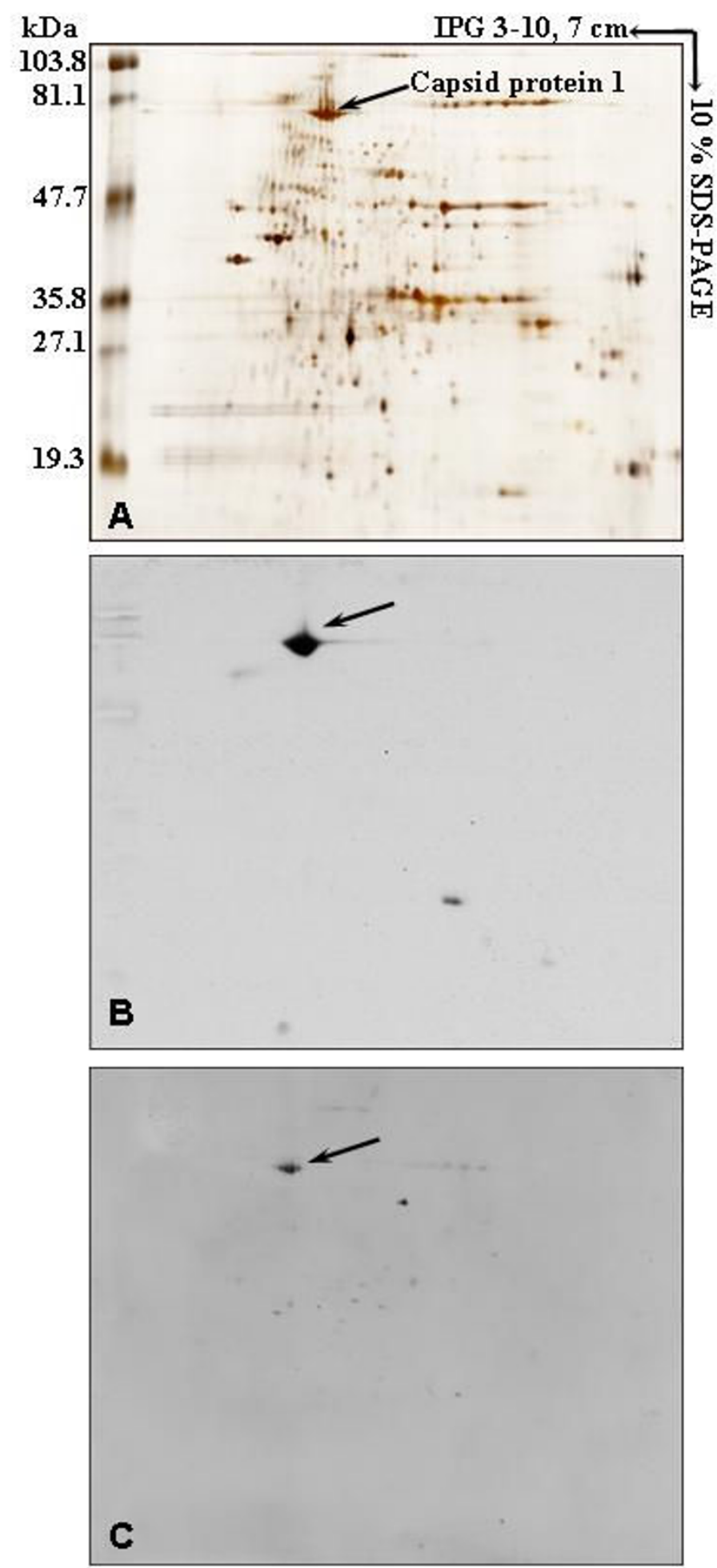

\section{Figure 3}

Two-dimensional gel analysis of APM associated proteins. Viral proteins were revealed by silver staining (A); by Western blot analysis using the Capsid protein I specific mAb P9A3 (B). Phosphorylated proteins were revealed with anti-Phosphoserine $\mathrm{mAb}(\mathrm{C})$. Standard molecular weight markers are indicated on the left. 
A
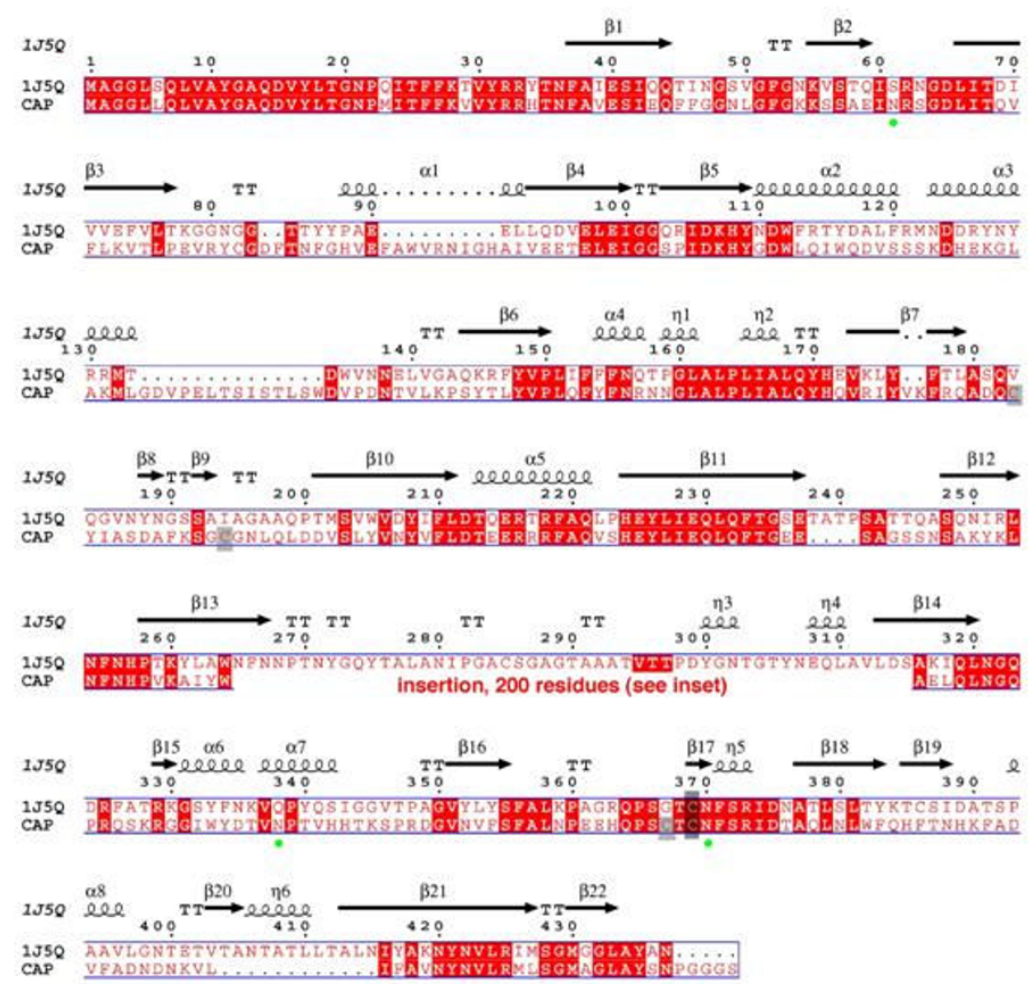

B

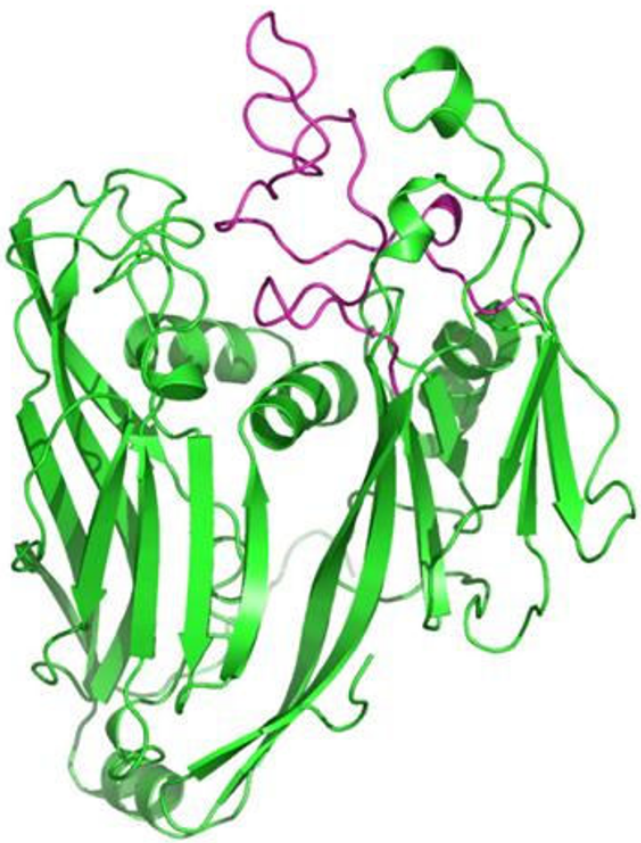

\section{Figure 4}

Sequence alignment and 3D modelling of APM Capsid protein I with that of Chlorella virus PBCVI. (A)

Sequence numbering is from the Chlorella virus capsid [PDB:IJ5Q]. The putative $\mathrm{N}$-glycosylation sites in APM Capsid are identified by green circles. An insertion of 200 AA replaces a coil motif in $115 \mathrm{Q}$ (positions 265-3I5) not belonging to the «jelly-roll») motifs. (B) 3D structure representation of Chlorella virus PBCVI Capsid core domain (green), and the coil domain (magenta) which is substituted in APM Capsid.

\section{Authors' contributions}

SA performed the experimental work; CC contributed structure prediction and analysis; MSM and DR conceived the study and wrote the paper. All authors read and approved the final manuscript.

\section{Acknowledgements}

This work was funded by CNRS. The authors would acknowledge the technical assistance of Claude Nappez for mice immunisation and preparation of monoclonal antibodies and of Gregory Gimenez for bioinformatics analysis.

\section{References}

I. La Scola B, Audic S, Robert C, Jungang L, de Lamballerie X, Drancourt $M$, Birtles $R$, Claverie JM, Raoult D: A giant virus in amoebae. Science 2003, 299:2033.

2. lyer LM, Aravind L, Koonin EV: Common origin of four diverse families of large eukaryotic DNA viruses. J Virol 200I, 75:11720-11734.

3. Raoult D, Audic S, Robert C, Abergel C, Renesto P, Ogata H, La Scola $B$, Suzan M, Claverie JM: The I.2-megabase genome sequence of Mimivirus. Science 2004, 306:1344-1350.

4. Suzan-Monti M, La Scola B, Barrassi L, Espinosa L, Raoult D: Ultrastructural characterization of the giant volcano-like virus factory of Acanthamoeba polyphaga Mimivirus. PLoS ONE 2007, 2:e328.

5. Xiao C, Chipman PR, Battisti AJ, Bowman VD, Renesto P, Raoult D, Rossmann MG: Cryo-electron microscopy of the giant Mimivirus. J Mol Biol 2005, 353:493-496.

6. Genbank [http://www.ncbi.nlm.nih.gov/sites/ent rez?db=genome\&cmd=search\&term $=N C$ 006450]

7. Renesto P, Abergel C, Decloquement P, Moinier D, Azza S, Ogata H, Fourquet $\mathrm{P}$, Gorvel JP, Claverie JM: Mimivirus giant particles incorporate a large fraction of anonymous and unique gene products. J Virol 2006, 80: I 1678-11685.

8. UniProtKB [http://www.uniprot.org/uniprot/Q5UQL7]

9. Spirin AS, Baranov VI, Ryabova LA, Ovodov SY, Alakhov YB: A continuous cell-free translation system capable of producing polypeptides in high yield. Science 1988, 242: I 162-I I64.

10. Near K, Stowers AW, Jankovic D, Kaslow DC: Improved immunogenicity and efficacy of the recombinant 19-kilodalton merozoite surface protein $I$ by the addition of oligodeoxynucleotide and aluminium hydroxide in a murine malaria vaccine model. Infect Immun 2002, 70:692-70I.

II. TBLASTN [http://] blast.ncbi.nlm.nih.goBlast.cgi?PAGE $=$ Translaons\&PRO=tblastn\&BLAS $T$ PROGRAMS $=$ tastn\&PAGE TYPE=BlastS earch\&SHOW DEFAULTS=on]

12. ExPASy proteomics server [http://www.cbs.dtu.dk/services/]

13. Van Etten JL: Unusual life style of giant Chlorella viruses. Ann Rev Genet 2003, 37:153-195. 
14. Benson SD, Bamford JK, Bamford DH, Burnett RM: Does common architecture reveal a viral lineage spanning all three domains of life? Mol Cell 2004, 16:673-685.

15. RCSB Protein Data Bank [http://www.rcsb.org/pdb/explore/ explore.do?structureld $=|| 5 \mathrm{O}]$

16. PSIPRED protein structure prediction server [http://bio inf.cs.ucl.ac.uk/psipred/]

17. Jones DT: Protein secondary structure prediction based on position-specific scoring matrices. J Mol Biol I999, 292:195-202.

18. McGuffin LJ, Bryson K, Jones DT: The PSIPRED protein structure prediction server. Bioinformatics 2000, 16:404-405.

19. Nandhagopal N, Simpson AA, Gurnon JR, Yan X, Baker TS, Graves MV, Van Etten JL, Rossmann MG: The structure and evolution of the major capsid protein of a large, lipid-containing DNA virus. Proc Natl Acad Sci USA 2002, 99: 14758- 14763.

20. Kutish GF, Li Y, Lu Z, Furuta M, Rock DL, Van Etten JL: Analysis of 76 kb of the Chlorella Virus PBCV-I 330-kb Genome: Map Positions I 82 to 258. Virology 1996, 223:303-307.

21. Yáñez RJ, Rodriguez JM, Nogal ML, Yuste L, Enriquez C, Rodriguez JF, Viñuela $E$ : Analysis of the complete nucleotide sequence of African Swine Fever virus. Virology 1995, 208:249-278.

22. Griffiths-Jones S, Moxon S, Marshall M, Khanna A, Eddy SR, Bateman A: Rfam: annotating non-coding RNAs in complete genomes. Nucleic Acids Research 2005, 33:D I2I-D I 24.

23. Zhou Y, Lu C, Wu QJ, Wang Y, Sun ZT, Deng JC, Zhang Y: GISSD: Group I Intron Sequence and Structure Database. Nucleic Acids Research 2008:D3I-D37.

24. Berger P, Papazian L, Drancourt M, La Scola B, Auffray JP, Raoult D: Ameba-associated microorganisms and diagnosis of nosocomial pneumonia. Emerg Infect Dis 2006, I 2:248-255.

25. La Scola B, Marrie T], Auffray JP, Raoult D: Mimivirus in pneumonia patients. Emerg Infect Dis 2005, I I:449-452.

26. Raoult $D$, Renesto $P$, Brouqui $P$ : Laboratory infection of a technician by Mimivirus. Ann Intern Med 2006, 144:702-703.

Publish with Biomed Central and every scientist can read your work free of charge

"BioMed Central will be the most significant development for disseminating the results of biomedical research in our lifetime. "

Sir Paul Nurse, Cancer Research UK

Your research papers will be:

- available free of charge to the entire biomedical community

- peer reviewed and published immediately upon acceptance

- cited in PubMed and archived on PubMed Central

- yours - you keep the copyright
BioMedcentral 